\title{
Kinetic Dissection of the Catalytic Mechanism of Taurine: $\alpha$-Ketoglutarate Dioxygenase (TauD) from Escherichia coli
}

John C. Price, ${ }^{a}$ Eric W. Barr, ${ }^{a}$ Lee M. Hoffart, ${ }^{a}$ Carsten Krebs, ${ }^{a, b, *}$ and J. Martin Bollinger, $\mathrm{Jr}^{\mathrm{a}, \mathrm{b}^{*}}$

Department of Biochemistry and Molecular Biology ${ }^{a}$ and Department of Chemistry, ${ }^{b}$ The Pennsylvania State University, University Park, PA 16802

Supporting Information:

Table S1

\begin{tabular}{|c|c|c|c|c|}
\hline$\delta(\mathrm{mm} / \mathrm{s})$ & $\Delta \mathrm{E}_{\mathrm{Q}}(\mathrm{mm} / \mathrm{s})$ & $\Gamma_{\text {left }}(\mathrm{mm} / \mathrm{s})$ & $\Gamma_{\text {right }}(\mathrm{mm} / \mathrm{s})$ & $\begin{array}{c}\text { Amount of TauD:Fe(II): } \alpha \text { KG:taurine } \\
\text { removed (\%) }\end{array}$ \\
\hline 1.17 & 2.59 & 0.45 & 0.46 & 25 \\
\hline 1.17 & 2.58 & 0.45 & 0.46 & 30 \\
\hline 1.17 & 2.56 & 0.45 & 0.46 & 35 \\
\hline 1.17 & 2.54 & 0.45 & 0.46 & 40 \\
\hline 1.18 & 2.52 & 0.45 & 0.46 & 45 \\
\hline
\end{tabular}

Table Legend:

Table S1: Parameters obtained from fitting reference spectra of the second intermediate to a quadrupole doublet. The reference spectra were generated by removing reference spectra of $\mathbf{J}(11 \%)$ and of the quaternary TauD•Fe(II)• $\alpha \mathrm{KG} \cdot$ taurine complex (amount given in last column) from the spectrum of the 200-ms sample. 
Figure S1

A

\section{TauD $\cdot \mathbf{F e}(\mathrm{II}) \cdot \alpha \mathrm{KG} \cdot$ Taurine}

$$
\varepsilon_{318}=0 \mathrm{M}^{-1} \mathrm{~cm}^{-1}
$$

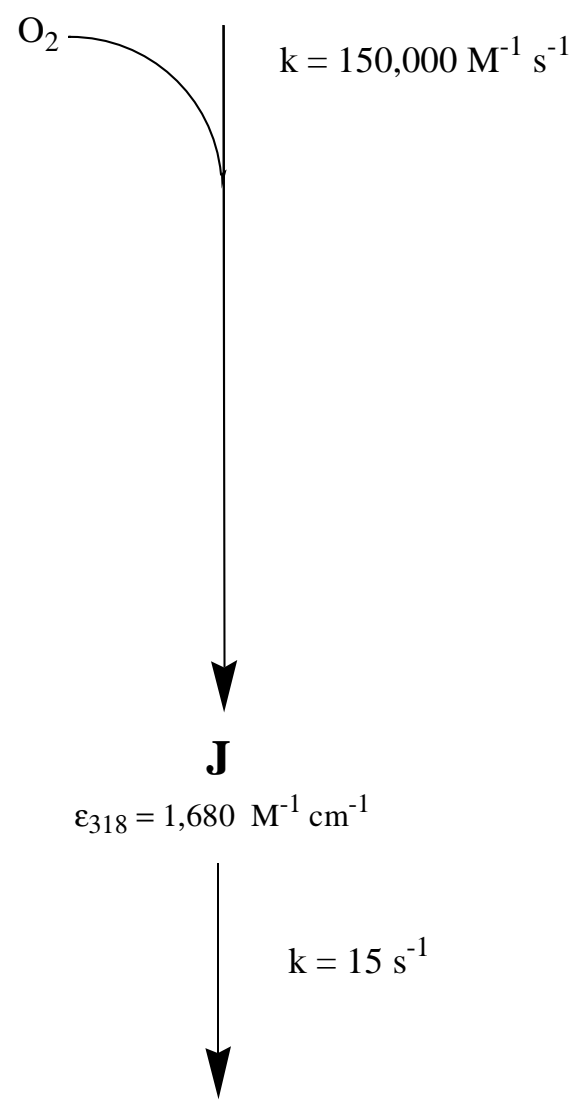

\section{$\mathrm{Fe}(\mathrm{II})$ intermediate}

$$
\varepsilon_{318}=0 \mathrm{M}^{-1} \mathrm{~cm}^{-1}
$$

B

TauD• Fe(II) $\bullet \alpha K G \cdot$ Taurine

$\varepsilon_{318}=0 \mathrm{M}^{-1} \mathrm{~cm}^{-1}$

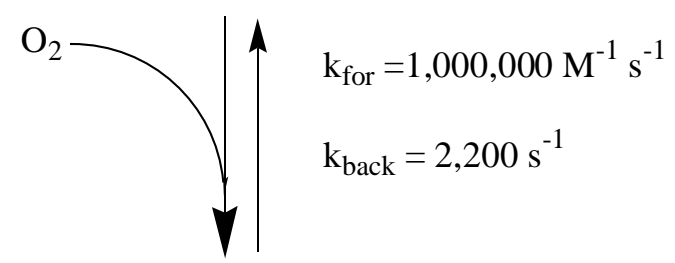

$\mathrm{O}_{2}$ adduct

$\varepsilon_{318}=1,500 \mathrm{M}^{-1} \mathrm{~cm}^{-1}$

$\mathrm{k}=415 \mathrm{~s}^{-1}$
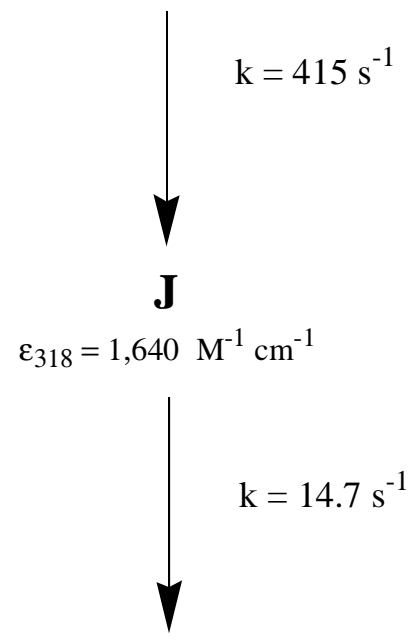

$\mathrm{Fe}($ II) intermediate

$\varepsilon_{318}=0 \mathrm{M}^{-1} \mathrm{~cm}^{-1}$

Figure S1: Kinetic mechanisms used to simulate the data presented in Figure 1, the three step mechanism (A) for panel A and the four step mechanism (B) for panel B. The product release step (decay of the Fe(II) intermediate) is omitted from these models because it has almost no effect on the simulations. 
Figure S2

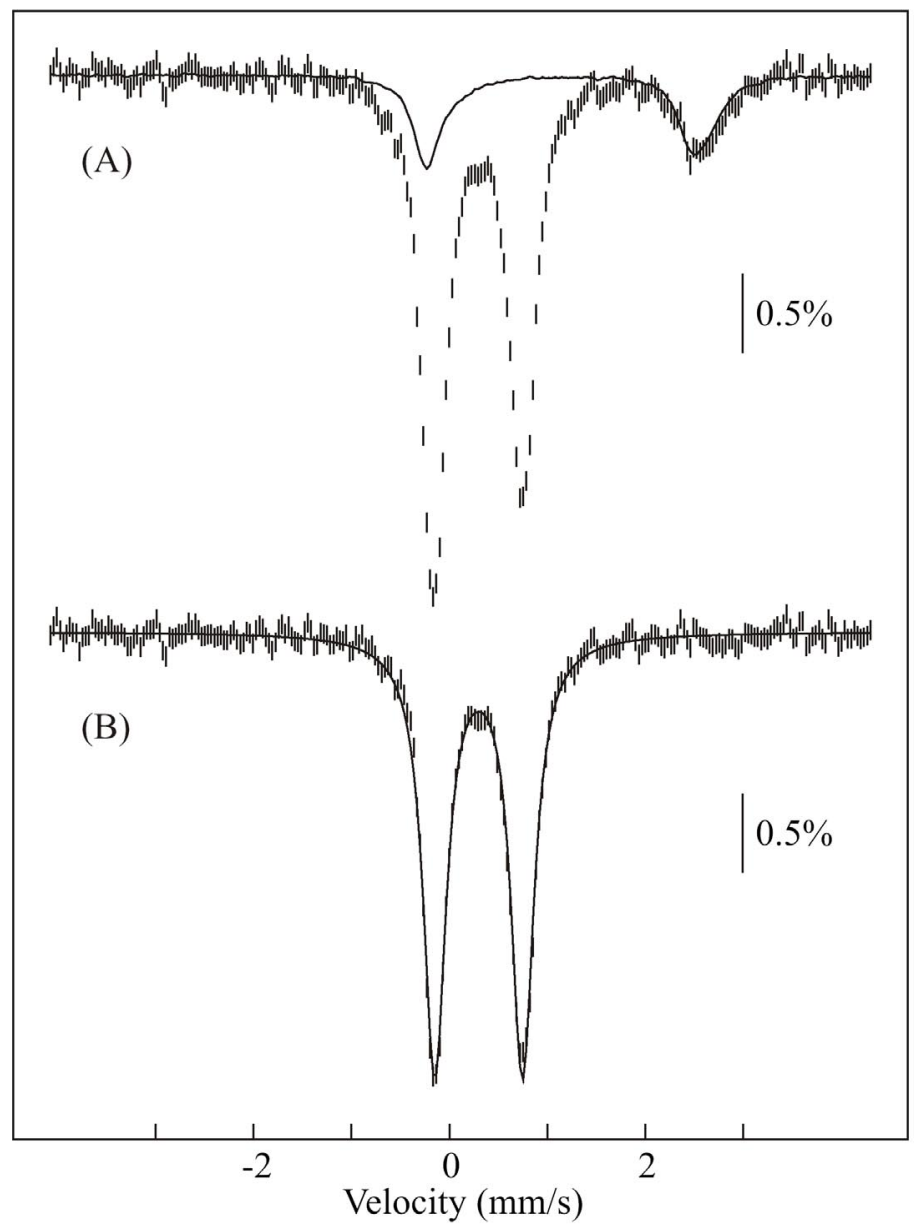

Figure S2: The reference spectrum of $\mathbf{J}$ was generated from the spectrum of a sample prepared by reaction of the TauD $\bullet F e(I I) \bullet \alpha K G \bullet 1,1-\left[{ }^{2} \mathrm{H}\right]_{2}$-taurine complex with $\mathrm{O}_{2}$ at $5{ }^{\circ} \mathrm{C}$ for $120 \mathrm{~ms}$ (final concentrations $2 \mathrm{mM}$ TauD, $1.8 \mathrm{mM}{ }^{57} \mathrm{Fe}(\mathrm{II}), 5$ $\mathrm{mM} \alpha \mathrm{KG}$ and 1,1-[ $\left.{ }^{2} \mathrm{H}\right]_{2}$-taurine, $0.95 \mathrm{mM} \mathrm{O}$ ) (A). Because the decay of $\mathbf{J}$ exhibits a large deuterium kinetic isotope effect $(\sim 35)$, the intermediate accumulates to a greater extent. Removal of the features of the quaternary complex, taken from Price, et. al. (2003) Biochemistry 42, 7497-7508, scaled to $20 \%$ of the total intensity (solid line in A), results in the reference spectrum of $\mathbf{J}$ (spectrum B, hash-marked). The solid line is a simulation using the following parameters: $\delta=0.30 \mathrm{~mm} / \mathrm{s}, \Delta \mathrm{EQ}=0.88 \mathrm{~mm} / \mathrm{s}$, and $\Gamma=0.28 \mathrm{~mm} / \mathrm{s}$. 
Figure S3

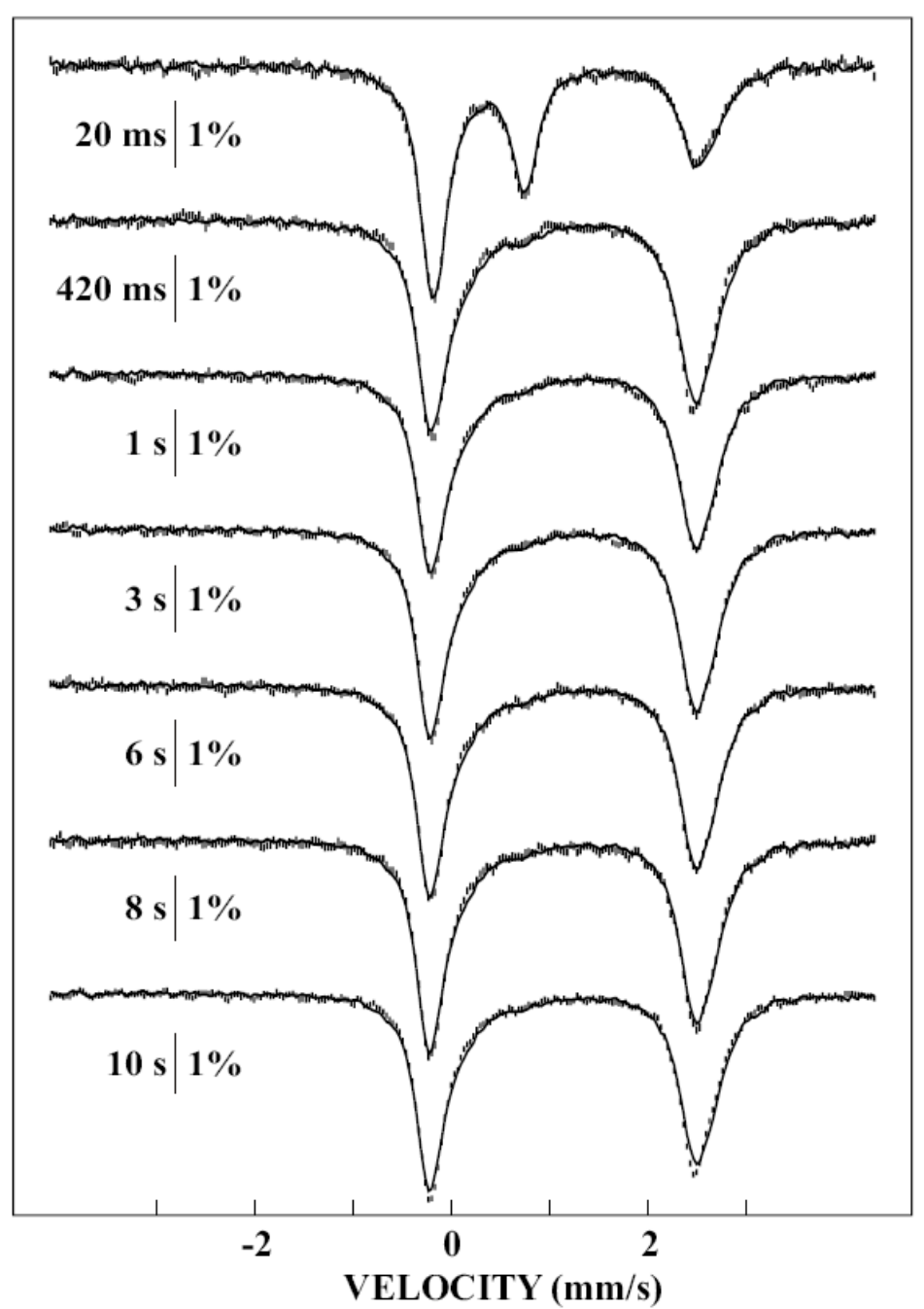

Figure S3: Mössbauer spectra of freeze-quenched samples of TauD recorded at $4.2 \mathrm{~K}$ in an externally applied 40-mT magnetic field. Concentrations after mixing were 1.6 mM TauD, $1.2 \mathrm{mM}{ }^{57} \mathrm{Fe}, 4.4 \mathrm{mM} \alpha \mathrm{KG}, 4.4 \mathrm{mM}$ taurine, and $1.3 \mathrm{mM} \mathrm{O}$. The reaction temperature was $5{ }^{\circ} \mathrm{C}$, and the reaction time for each sample is given on the figure. The hash marks are the experimental data, and the solid lines are linear combinations of reference spectra representing the quaternary complex, $\mathbf{J}$, and the second intermediate, with the coefficients given in Table 1. 